\title{
Mayor mortalidad de pacientes que inician tratamiento antiretroviral en países de bajos ingresos
}

Braitstein P y col. Lancet 2006; 367:817-824.

\begin{abstract}
Objetivo
Comparar la mortalidad temprana, respuesta inmunológica y virológica en participantes de cohortes similares de adultos con infección por VIH (virus de inmunodeficiencia adquirida) sin tratamiento antiretroviral previo (TARp) que iniciaron TAR altamente efectivo (HAART de sus siglas en inglés: highly active antiretroviral therapy) en países de bajos y altos ingresos.
\end{abstract}

\section{Diseño}

Estudio de cohortes con grupo de comparación exterior.

Lugar

Países de bajos ingresos (PBI) de África, Asia y Sudamérica y países de altos ingresos (PAI) de Europa y Norteamérica.

\section{Población}

Adultos con VIH sin TARp con fecha conocida de inicio de HAART y documentación basal de linfocitos CD4: 4.810 pacientes $(74 \%$ de 6498 elegibles que tenían CD4 basal documentado) de 18 programas de TAR de PBI con recolección prospectiva de datos; y 22.217 pacientes de 12 cohortes de PAl cuya base de datos desde el año 2001 estima pronóstico de pacientes sin TARp que inician HAART.

\section{Medición de resultados}

Cada centro seleccionó los pacientes y los datos fueron incorporados a una base de datos común en forma anónima. El objetivo primario fue evaluar la mortalidad en el primer año de HAART (cualquier causa). Los objetivos secundarios fueron el cambio de CD4 y el porcentaje de pacientes con carga viral $<500$ a 6 meses.
Se realizó monitoreo de carga viral en el $50 \%$ de los pacientes. Se logró el seguimiento activo de 2725 (57\%) de pacientes de PBI y $100 \%$ de PAI.

\begin{abstract}
Resultados
Los pacientes de PBI (vs. PAI) tenían menor recuento de CD4 por uL (108 vs 234), mayor porcentaje de mujeres (51\% vs $25 \%$ ) y mayor tratamiento inicial que incluía inhibidor no-nucleósido de la transcriptasa inversa (70 vs $23 \%$ ). La mortalidad a un año en los PBI fue de $6.4 \%$ (IC95 \% 5,1 a 7,7\%) y en los PAI de 1,8\% (IC95\% 1,5 a 3,2). El riesgo de mortalidad ajustado (Hazard Ratio*) comparando PBI vs PAI bajó de 4,3 (IC95\% 1,6 a 11,8) el primer mes a 1,5 (IC95\% 0,7 a 3,0) en los meses 7-12. La provisión de tratamiento gratuito en PBI se asoció a una menor mortalidad (HR ajustado 0,23; IC95\% 0,08 a 0,61). No hubo diferencias entre los diferentes esquemas de HAART. A los seis meses de HAART los siguiente resultados fueron similares entre PBI y PAl: mediana de aumento de CD4 (106 vs $103 \mathrm{cel} / \mathrm{uL}$ ) y porcentaje de pacientes con carga viral indetectable (76 vs 77\%). En los primeros 6 meses ocurrieron $78 \%$ y $62 \%$ de las muertes de los pacientes de PBI y PAI respectivamente.
\end{abstract}

\section{Conclusiones}

La mayor mortalidad durante los primeros meses de los pacientes que inician HAART en PBI comparado con los PAl podría disminuir con diagnóstico y detección temprana de los pacientes pasibles de tratamiento y con el acceso gratuito a la medicación.

Fuente de Financiamiento: No se refiere

\section{Comentario}

A pesar de las limitaciones de este estudio en relación a los programas de PBI: exclusión de $26 \%$ de pacientes sin CD4 basal, pérdida de $12 \%$ en programas con seguimiento activo (no diferencias en CD4 basal entre los pacientes perdidos o no para el seguimiento), este estudio muestra que pacientes con VIH sin TARp al inicio del HAART tienen mayor deterioro de la inmunidad que pacientes de PAI, pero obtienen similar respuesta inmunológica y virológica a los seis meses, reduciendo luego el exceso de mortalidad inicial. Esta mayor mortalidad al comienzo se explica parcialmente por los CD4 más bajos, pudiendo haber contribuido también comorbilidades como la tuberculosis.

Este hallazgo coincide con un metaanálisis que encontró carga viral indetectable a 12 meses del TAR en el $57 \%$ en pacientes de $\mathrm{PBI}$, similar a lo reportado en pacientes de PAl'.

La combinación de tres drogas antirretrovirales para infección por VIH (TAR altamente efectivo, HAART) ha cambiado significativamente el pronóstico de los pacientes desde su introducción en 1996 en los pacientes que tuvieron acceso a la medicación. Sin embargo, se estima que en el mundo hay 40 millones de personas infectadas por VIH y solo uno de cada cinco pacientes de países de medianos y bajos ingresos que requieren TAR lo están recibiendo, las dificultades financieras y de provisión de medicación comprometen el inicio y adherencia adecuados ${ }^{2}$

En la Argentina, hasta diciembre 2005 había 32.411 casos notificados de infección por VIH al Programa Nacional de SIDA, pero se calcula que hay 127.000 infectados, de los cuales el $60 \%$ desconoce su situación serológica. A partir 1997 comienza a difundirse en nuestro país el uso del HAART ${ }^{3}$.

Conclusiones del comentador

Las recomendaciones internacionales de la Sociedad de SIDA para el inicio de TAR incluye pacientes sintomáticos y en asintomáticos considerarlo con $<350$ CD4 y antes de que caigan por debajo de $200^{4}$.

Para esto es importante un diagnóstico precoz y acceso a medicación gratuita.

Estela Salazar Schicchi [ Sección Infectología. Hospital Italiano Buenos Aires. ]

Salazar Schicchi E. Mayor mortalidad de pacientes que inician tratamiento antiretroviral en países de bajos ingresos. Evid. actual. pract. ambul. 9(5);136. SepOct. 2006. Comentado de: Mortality of HIV-1-infected patients in the first year of antiretroviral therapy: comparison between low-income and high-income countries. The Antiretroviral Therapy in Lower Income Countries (ART-LINC) Collaboration and ART Cohort Collaboration (ART-CC) groups. Lancet 2006; 367:817-824. PMID: 16530575

Referencias

1. Ivers L, Kendrick D, Doucette K. Efficacy of antiretroviral therapy programs in resource-poor settings: a meta-analysis of the published literature. Clinical Infectious Diseases 2005; 41:217-24

2. Merson M. The HIV-AIDS Pandemic at 25-The global response. NEJM 2006; 354: 2414

3. Boletín sobre VIH/SIDA en la Argentina. Año X Número 24 -Diciembre 2005: Ministerio de Salud de la Nación.

4. Hammer S, Saag M, Schechter M y col. Treatment for adult HIV infection. 2006 recommendations of the International AIDS Society-USA Panel. JAMA 2006; 296: 827843 